\title{
TARSAL BONE DISINTEGRATION IN LEPROSY
}

\author{
Grace Warren, Hong Kong \\ From the Hay Ling Chau Leprosarium, Hong Kong
}

Many of the foot deformities that cause marked disability in patients with leprosy have resulted from disintegration of the tarsal bones. This condition has been observed by a number of workers in different countries, but is often accepted as a progressive disorder that does not respond to treatment.

These lesions have been only briefly dealt with in the literature. Some of the references were mentioned by Harris and Brand (1966), who stated that it was difficult to stop rapid destruction of the foot once tarsal disintegration had begun. This is the general impression given by other workers, but a detailed study of the natural history in Chinese patients has shown that treatment is effective and that long-term results are satisfactory. The results of this study are summarised here.

\section{MATERIAL}

The case histories and radiographs of over 1,500 leprosy patients treated at the Hong Kong Leprosarium since 1959 were available for the study of tarsal bone disintegration. Of these patients, 400 admitted consecutively have been examined to provide prevalence rates and to indicate the persons at risk.

\section{NATURAL HISTORY}

The presenting signs are usually heat and swelling of the foot or ankle, without pain. Sepsis is not commonly present. Rarely a history of injury, such as a sprain, is elicited.

The first radiographic evidence is detectable four to six weeks after the presenting signs are observed. There may be a minimal fracture, either chip or crack (Paterson and Job 1964), rarefaction, fragmentation or partial collapse. These bone lesions progress, sometimes with absorption or displacement of the fragments and collapse with consequent deformity of the foot.

The clinical signs of heat and swelling persist for several months, but as the process becomes more chronic the heat subsides and deformity becomes more obvious. Eventually the foot may show no heat and little or no swelling but the patient may have marked deformity, hypermobility or instability that is incompatible with normal function.

\section{ILLUSTRATIVE CASE REPORTS}

Case 1-A man aged thirty-eight was found to have slight irregularity of the talus in September 1957 (Fig. 1). The treatment recommended was relief of weight-bearing by use of crutches, but as his hands were badly deformed this was not practicable and limited walking continued. The lesion progressed over four months until a marked deformity of the ankle was present (Fig. 2). The foot was later amputated.

Case 2-A man aged twenty-five was found to have destruction of the talus and adjacent bones (Fig. 3). In spite of irregular immobilisation and periods of relief from weight-bearing the lesion progressed to complete disorganisation of the ankle and adjacent tarsal bones (Fig. 4).

Osteoclastic and osteoblastic activity have been seen to occur side by side in biopsy material, and it has been observed that healing tends to occur when the affected foot is completely immobilised. 
Careful observation has shown that in some patients episodes of bone breakdown have alternated with periods of healing. Healing has occurred during immobilisation in a walking plaster or enforced rest in bed, but has been interrupted by resumption of normal activity, when breakdown has occurred again. Lesions have been seen in which severe deformity and

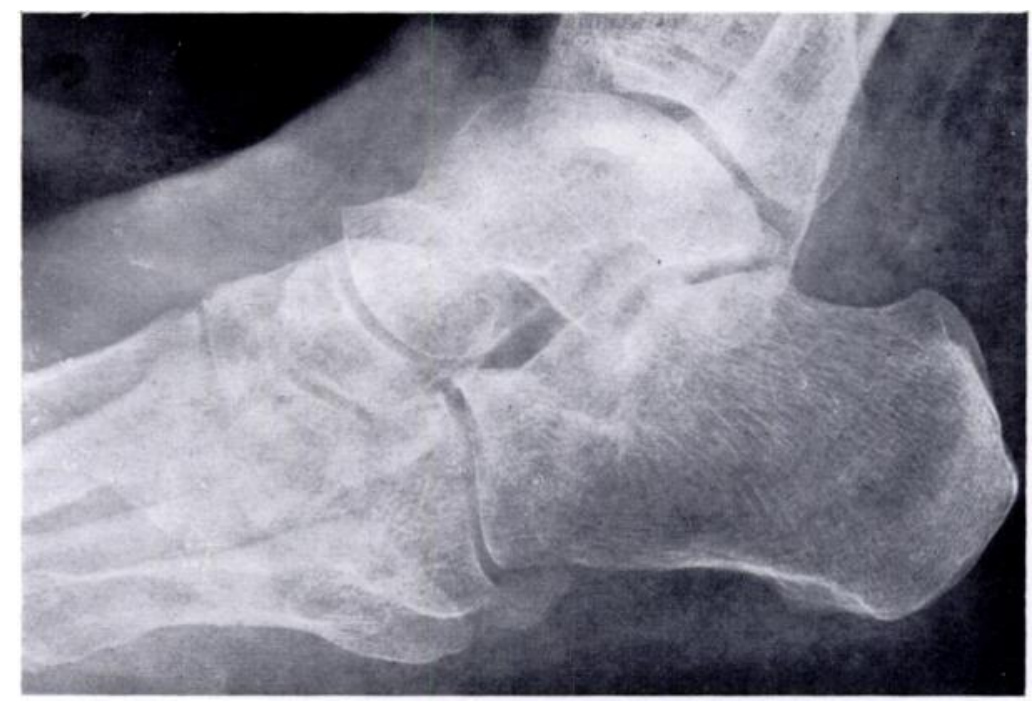

FIG. 1

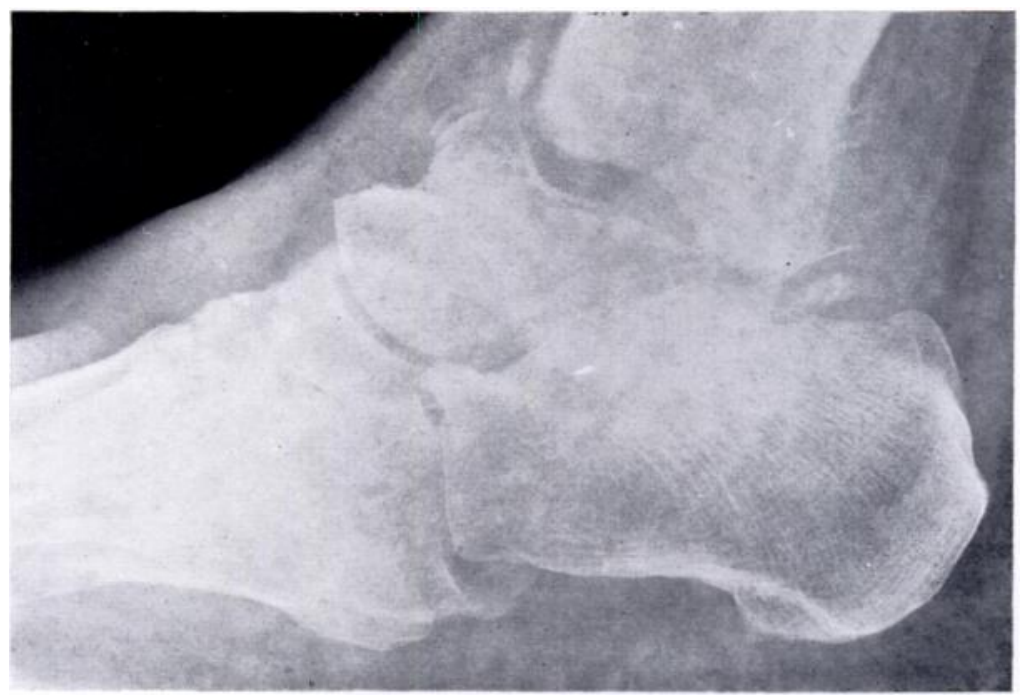

FIG. 2

Case 1. Figure 1-- Early irregularity of the talus in September 1957. Figure 2January 1958: collapse of the talus.

instability have occurred within three years of a radiograph showing normal appearances. In other patients, in spite of a degree of low grade activity continuing for many years, the foot has remained basically functional while showing slowly increasing deformity. Radiographs covering a period of thirteen years are available for one patient, who retains a functional though deformed foot.

VOL. 53 B, NO. 4, NOVEMBER 1971 


\section{PREVALENCE}

For the determination of prevalence rates all types of tarsal bone lesion are included (Table I). The lesions appeared to be more common in patients with unstable dimorphous leprosy than in patients with other forms. This may be due to the high incidence of lepra reaction and nerve involvement in these patients.

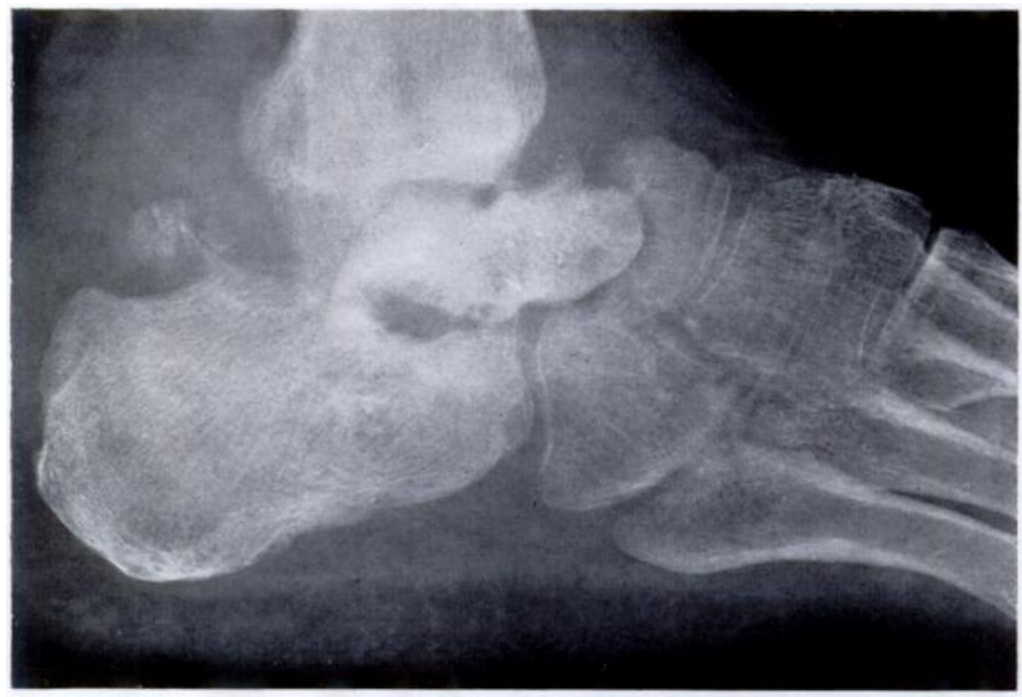

Fig. 3

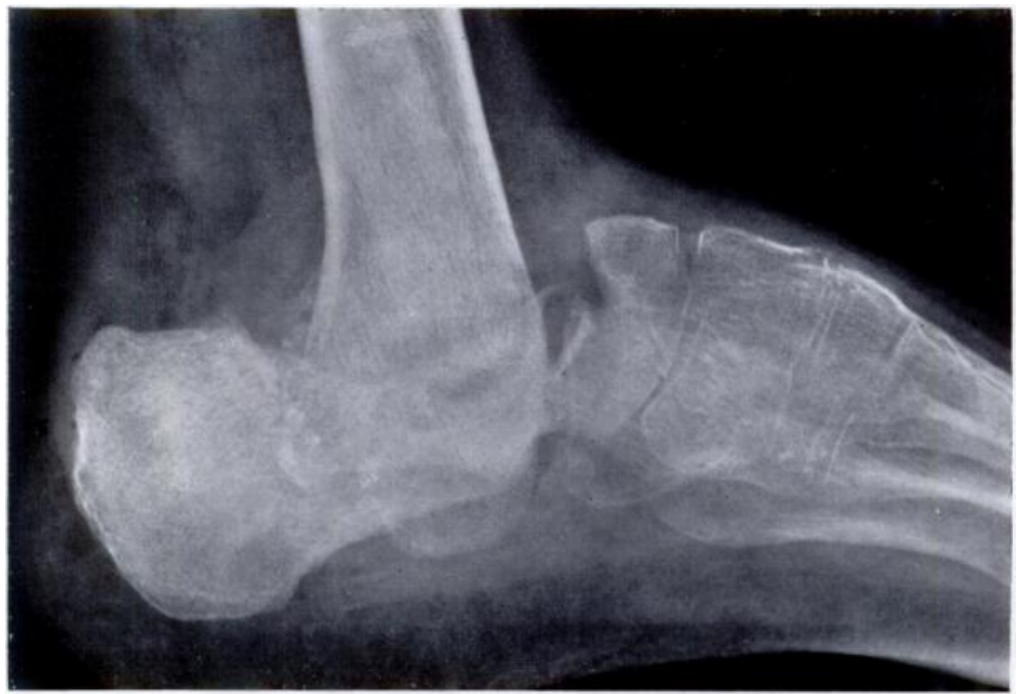

Fig. 4

Case 2. Figure 3-Marked disintegration of the talus. Figure 4-Progress of destruction: weight is now borne directly on the tibia.

It was observed that of the forty-four patients in the selected group who had walking plasters, 11 per cent developed tarsal bone disintegration on removal of the plaster.

A study of these 400 patients has indicated that the patients at risk are those with conditions that predispose to osteoporosis. Some of these conditions have been implicated by other workers (Table II). 
The osteoporosis so caused is sufficient to increase the risk of a stress fracture from microtrauma (Paterson 1961). On a number of occasions tarsal bone disintegration has been seen to follow attempted arthrodesis of the ankle or fracture of the ankle or foot when immobilisation has been discontinued before healing was complete.

TABLE I

Prevalfnce of Tarsal Bone Lesions in Patients Suffering from Leprosy

\begin{tabular}{|c|c|}
\hline Total number of patients & 400 \\
\hline Patients showing tarsal bone lesions & $94(23.5$ per cent $)$ \\
\hline Patients showing unilateral foot involvement & 76 (19 per cent $)$ \\
\hline Patients showing bilateral foot involvement & $18(4 \cdot 5$ per cent $)$ \\
\hline Total number of affected feet & $112(14$ per cent $)$ \\
\hline Total number of tarsal bone lesions seen . & 119 \\
\hline Number of lesions active on admission of patient & 19 \\
\hline $\begin{array}{l}\text { Number of lesions that developed whilst patient } \\
\text { was under treatment }\end{array}$ & 22 \\
\hline
\end{tabular}

TABLE II

Conditions Predisposing to Osteoporosis

\begin{tabular}{|c|c|}
\hline \multicolumn{2}{|c|}{ Hyperaemia of the feet caused by 1 ) lepra reaction } \\
\hline & $\begin{array}{l}\text { 2) sepsis (Harris and Brand 1966) } \\
\text { (Karat and colleagues 1968) }\end{array}$ \\
\hline \multirow[t]{4}{*}{$\begin{array}{l}\text { Prolonged limitation of walkir } \\
\text { caused by }\end{array}$} & $\begin{array}{l}\text { with atrophy and osteoporosis (Price 1964) } \\
\text { 1) lepra reaction (Karat et al. 1968) }\end{array}$ \\
\hline & $\begin{array}{l}\text { 2) ulceration of the feet treated by complete } \\
\text { bed rest }\end{array}$ \\
\hline & 3) operation \\
\hline & 4) intercurrent illness \\
\hline \multirow[t]{2}{*}{ Corticosteroid medication for } & 1) lepra reaction \\
\hline & 2) intercurrent illness \\
\hline Plaster for treatment of & $\begin{array}{l}\text { ulceration of the foot and other conditions } \\
\text { (Price 1964) (Harris and Brand 1966)(Lennox } \\
\text { 1965) }\end{array}$ \\
\hline
\end{tabular}

\section{ETIOLOGY}

The radiographic evidence supports the view that tarsal bone disintegration is the result of microtrauma (Harris and Brand 1966), possibly in the shape of stress fractures (Karat, Karat and Foster 1968) which are neglected because of the diminution of pain perception (Paterson and Job 1963). The incidence of microtrauma and stress fracture is probably increased by the osteoporotic condition of the feet of the patients at risk (Table II). Disintegration of tarsal bones is often regarded as a neurotrophic lesion. This is supported by clinically detectable anaesthesia in 79 per cent of the affected legs in the selected group, although lesions have occurred in patients who have no detectable nerve deficit.

VOL. $53 \mathrm{~B}$, NO. 4, NOVEMBER 1971 


\section{TREATMENT}

Healing of these bone lesions will occur if the foot is adequately immobilised for long enough. This was reported by Harris and Brand (1966), who also mentioned that disintegration progressed during the use of calipers and other weight-relieving appliances.

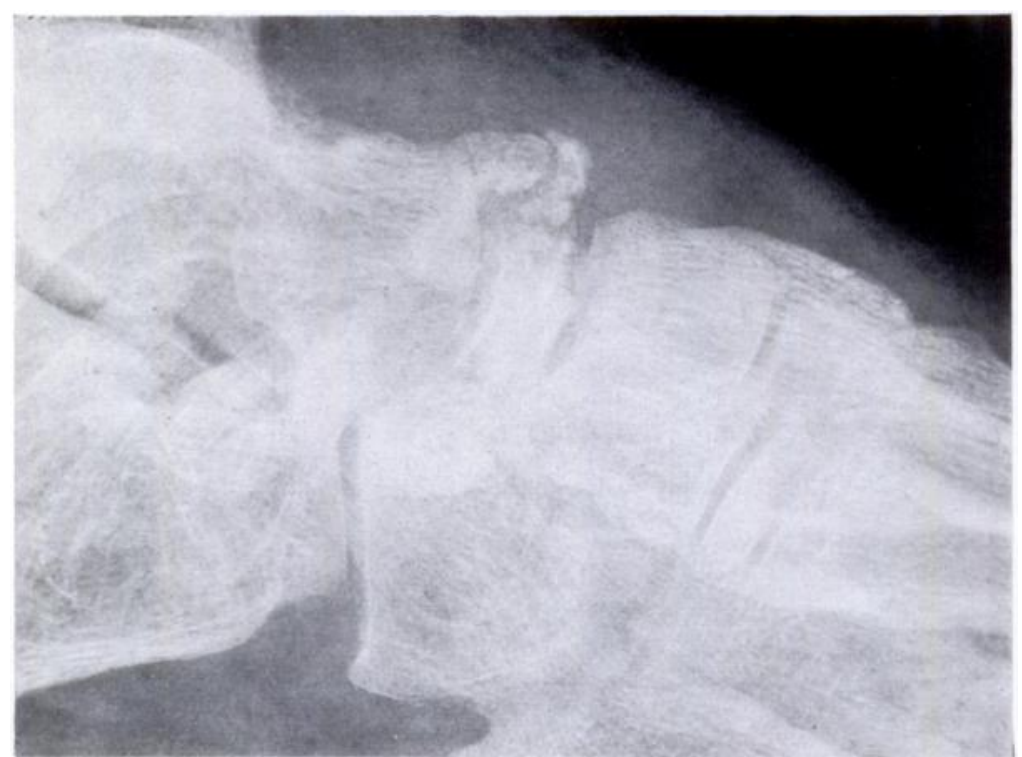

FIci. 5

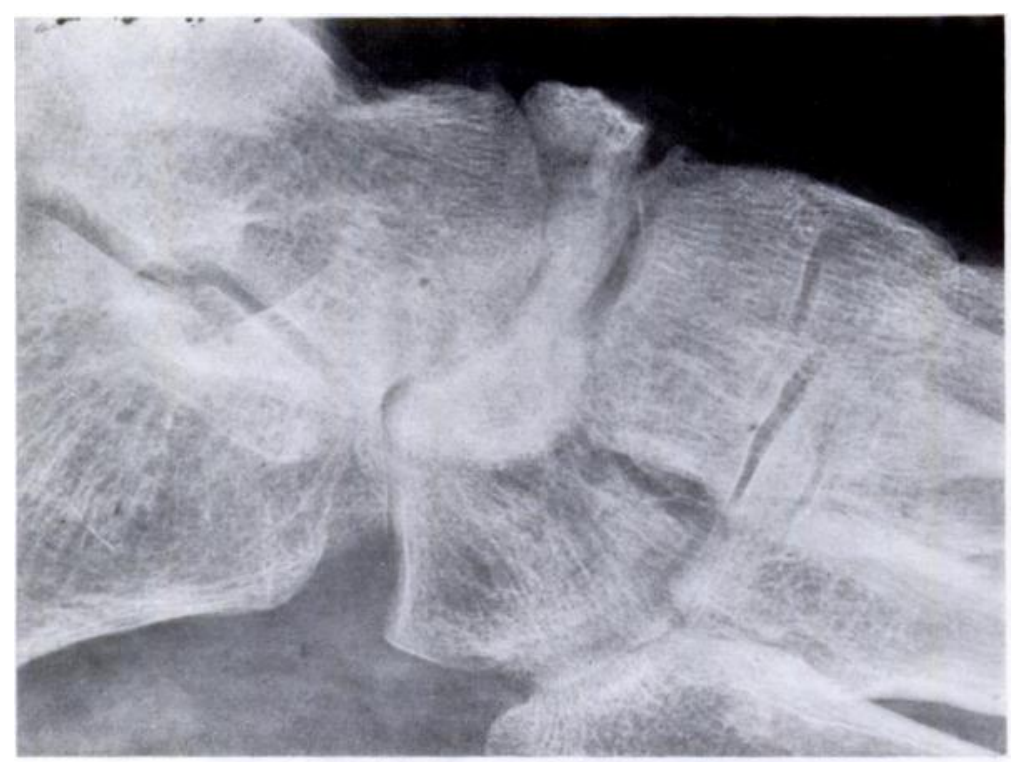

Fig. 6

Case 3. Figure 5-Early disintegration of navicular bone. Figure 6-Healing after six months' immobilisation.

\section{ILLLSTRATIVE CASE REPORTS}

Case 3-A man aged thirty-five with navicular disintegration (Fig. 5) was treated by immobilisation of foot and calf in a plaster-of-Paris walking cast for six months. Complete healing of the lesion occurred and the foot remained stable for ten years (Fig. 6).

THE JOURNAL OF BONE ANI) JOINT SURGIRY 
Case 4-A girl aged sixteen had a small chip fracture of the head of the talus (Fig. 7). Treatment was given irregularly over two years: there were periods of complete immobilisation on several occasions during which bone healing occurred; at other times, when weight-relieving calipers and crutches were used, further disintegration and collapse were observed. Healing eventually resulted but after further destruction with collapse of the head of the talus and loss of the longitudinal arch of the foot (Fig. 8).

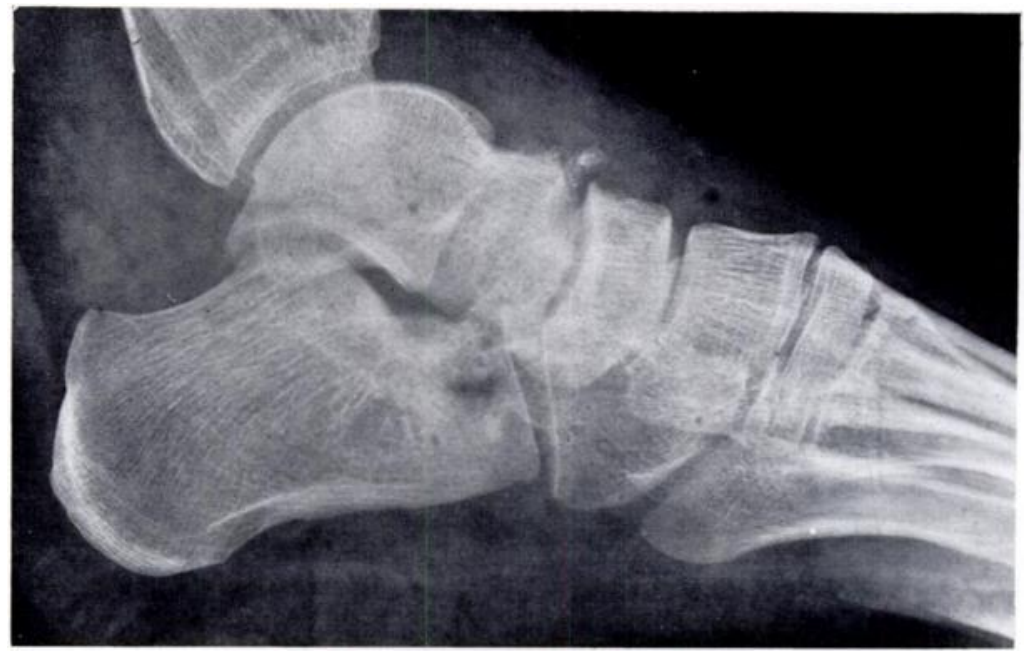

FIG. 7

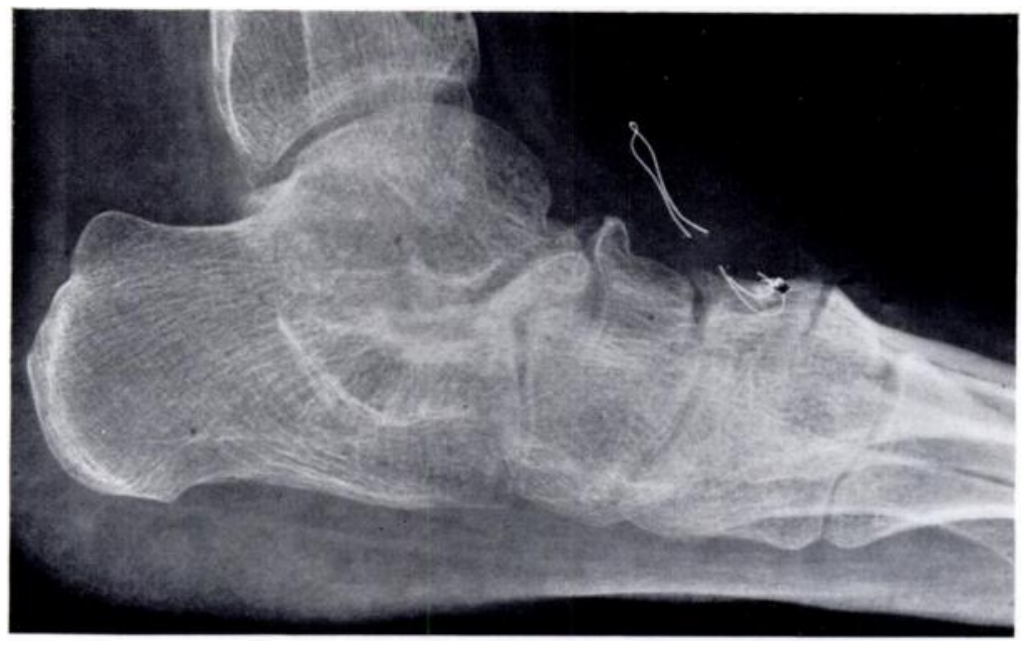

FIG. 8

Case 4. Figure 7-Minimal fracture of head of talus. Figure 8-Healing with deformity of head of talus and collapse of longitudinal arch.

It is important that a well planned plaster be applied to prevent the development of further collapse of the osteoporotic bones. In those lesions in which hypermobility of the foot exists it may be possible to mould the foot into a better functional shape while the plaster is being applied. The writer does not recommend operation for early lesions or when the foot can be moulded into a functional position. Lesions will heal without operation and this is encouraged when possible.

In patients with healed or partially healed lesions but grossly deformed feet that cannot be moulded into a functional shape, it may be advisable to improve the shape by operation. 
Osteotomies or bone grafts can be used as necessary (Lennox 1965). Healing does occur but may take twelve to eighteen months before it is complete. Adequate immobilisation must be maintained till the lesion is fully healed.

In the early minimal lesion healing may be complete in four to six months. Most moderately severe lesions require about nine months of immobilisation and surgical cases at least nine months.

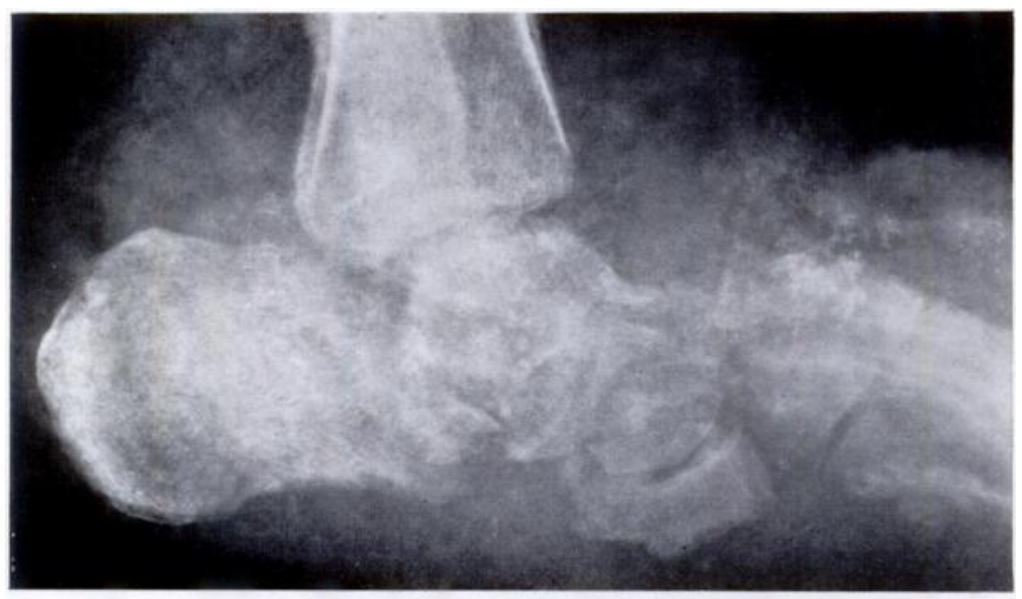

FIG. 9

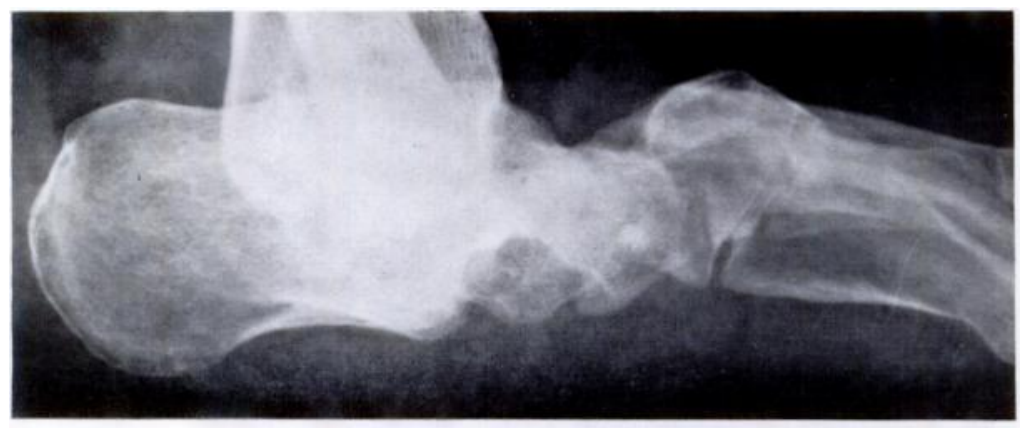

FIG. 10

Case 5. Figure 9-Bone disintegration with infection. Figure 10-Complete healing within a year.

Disintegration rapidly begins again if the lesion is not fully healed when walking is resumed. Hence it is essential that radiographic bone healing be achieved and after that a period of trial walking be undertaken. The patient is allowed to walk for short periods, three to five minutes at a time the first day, and the time is gradually increased if there is no heat or swelling. Renewed heat and swelling suggest reactivation and should be treated by a walking cast for a further six to eight weeks, after which trial walking is again permitted.

If sepsis is present it is important to maintain a functional position during its resolution or more deformity may result. It is desirable to immobilise completely as soon as the discharge decreases enough to allow a plaster cast to be applied. Final healing is not usually delayed, provided the position is satisfactory.

\section{CASE REPORT}

Case 5-A man aged forty-five was admitted with sepsis of the left foot and marked bone involvement (Fig. 9). Local treatment, antibiotics and complete immobilisation resulted in bone healing with a useful though deformed foot (Fig. 10). 


\section{RESULTS}

Healing of lesions has been seen in all patients who would cooperate and persist with walking plasters. Some early lesions have now remained healed for over ten years. Although in some patients a second bone has been involved in the same foot, in no case has the same bone been involved on a second occasion once complete healing and walking were achieved.

A number of markedly deformed feet have been reshaped by operation, and no further breakdown in the affected areas has occurred during a five-year follow-up.

\section{CONCLUSIONS}

Tarsal bone disintegration can be a very disabling condition and left untreated it predisposes to many of the chronic foot problems of leprosy patients.

Most patients with tarsal bone disintegration can be treated satisfactorily to ensure a useful foot. Amputation is only necessary in neglected patients with gross deformity, extensive loss of bone or widespread scarring.

\section{SUMMARY}

1. Tarsal bone disintegration is a progressive disorder that affects a high proportion of leprosy patients.

2. Early detection and treatment by immobilisation permit healing with minimal deformity or disability.

3. Feet with advanced lesions can be similarly treated with a satisfactory outcome and amputation is not needed.

\section{REFERENCES}

Harris, J. R., and Brand, P. W. (1966): Patterns of Disintegration of the Tarsus in the Anaesthetic Foot. Journal of Bone and Joint Surgery, 48-B, 4.

Karat, S., Karat, A. B. A., and Foster, R. (1968): Radiological Changes in Bones of the Limbs in Leprosy. Leprosy Review, 39, 147.

Lennox, W. M. (1965): The Surgical Management of Foot Deformities in Leprosy. Leprosy Review, $36,27$.

Paterson, D. E. (1961): Bone Changes in Leprosy. Their Incidence, Progress, Prevention and Arrest. International Journal of Leprosi, 29, 393.

Patfrson, D. E., and Job, C. K. (1964): Bone Changes and Absorption in Leprosy. In Leprosy in Theory and Practice. Second edition, p. 422. Edited by R. G. Cochrane and T. F. Davey. Bristol: John Wright \& Sons Ltd.

Pricf, E. W. (1964): The Etiology and Natural History of Plantar Ulcer. Leprosy Review, 35, 259. 